Available online @ https://jiem.jnnce.ac.in

https:www.doi.org/10.37314/JJEM.2021.050102

Indexed in International Scientific Indiexing (ISI)

Impact factor: 1.025 for 2018-19

Published on: 30 September 2021

\title{
All in One Card: A Knowledgeable Tool
}

\author{
Sudha Ayatti ${ }^{1}$, Gouri Khadabadi ${ }^{2}$, S.P. Bangarshetti ${ }^{3}$, Pavan N. Kunchur ${ }^{4}$ \\ ${ }^{1,2,4}$ Department of CSE, KLS, Gogte Institute of Technology, Belagavi, Karnataka \\ ${ }^{3}$ Department of ISE, Basaweshwar Engineering College, Bagalkot, Karnataka \\ shayatti@git.edu,gckhadabadi@git.edu, spbis@becbgk.edu,pnkunchur@git.edu
}

\begin{abstract}
Almost a decade ago, we could all have heard of the smart card and its role in the financial sector, especially for retail transactions. The smart card provides special security compared to normal monetary transactions. But its implementation in the case of retail payments has not been as popular. But it was really useful in the area of transit payments and personal identification. But some other sectors, such as mobile telecommunications, found this more useful and began using them in mobile phones as subscriber identification modules (SIMs). But in today's world, people need to carry different cards like PAN cards, driver's licenses, Aadhaar cards, etc., which makes people more uncomfortable as they have to carry different cards at the same time.
\end{abstract}

Keywords: Subscriber Identification Module, PAN card, Aadhaar Card

\section{Introduction}

Practically 10 years earlier we in general would have found out about the keen card and its part in the cash related region, especially for retail trades. Smartcard gives a phenomenal security when diverge from regular money trade. However, its use because of Retail portions has not been so standard. Be that as it may, it found really significant in the domain of movement portions and Personal Identification. In any case, some various territories like flexible media transmission found this more supportive and started using in Mobile phones as a Subscriber Identification Modules (SIM). Notwithstanding, in the current world people need to pass on different cards like PAN Cards, Driving Licenses, Aadhaar Card, etc. which make the people more abnormal as they have to pass on different cards all the while. The microchip can store the sufficient amount of data so that all the details can be easily stored.

\section{Objectives}

- To develop an application this provides assistance to user for identity of any documents.

- Helping the people to avoid paying penalties.

- To develop a system which stores all the information in a single card and easily accessible to the user

- To develop the system to provide necessary information in a single click.

\section{Literature survey}

The broad accessibility and advantageous utilization of credit and charge cards for general money related exchanges have multiplied the quantity of these plastic cards or budgetary instruments all through the world [1]. Alongside the Advantages and usability, these modest and promptly accessible cards are exceptionally defenseless to unapproved use and robbery. Security relies upon keeping up close to home ownership of the cards and limiting 
admittance to the record numbers however much as could be expected.Moreover, Visa robbery is additionally convoluted by the age and adulteration of these cards with illicitly acquired individual recognizable proof numbers. Simple and solid intends to approve that the card is forged.

A device for a computer is described having two circuit boards in which plug connectors for plug-in cards are present protruding above the circuit boards with a first height [3]. There is a bridge card that connects to the two circuit boards, connecting the two circuit boards electrically and protruding above the circuit boards with a second height. According to this invention, the bridge card is connected to the two circuit boards independently of the plug connectors and the first height is greater than the second height [4]. This invention relates to a computer device having at least two circuit boards on which there are plug-in connectors, for plug-in boards, which protrude at a first height above the circuit boards, and which has a bridge board that is connects the two. circuit boards and by means of which the two circuit boards are electrically connected to each other, and which projects to a second height above the circuit boards [5]. This invention also relates to a corresponding bridge card for a computer.

Such a device [6], [7] is known for use with a personal computer, for example, in which two so-called bus cards are electrically and functionally connected to each other via a bridge card. With the help of a bridge card, it is possible to increase the number of plug-in slots available for the bus cards. Plug-in cards, such as adapter cards for devices connected to the computer, can be plugged into these plug-in slots.

The bridge card is known to be equipped with mating connectors, which can be inserted into the plug-in connectors of the two circuit boards. When plugged in, the bridge card occupies one connector on each of the two circuit boards [10].

The bridge card is generally provided with an integrated chip, which provides the electrical and functional connection for the two circuit boards. In particular, the chip is suitable for generating selector signals for selecting certain socket slots and transmitting them between circuit boards.

As a result of the structural size of the chips, the bridge card covers not only the two connectors on the circuit boards on which it is installed, but also the next two plug connectors on the two circuit boards. This means that the bridge card occupies a total of four connectors on the two circuit boards instead of just two.

The disadvantage of the known bridge card is therefore that its presence is automatically associated with pluggable slots on both circuit cards that are occupied. Consequently, additional cards may not be plugged into these plug-in slots, so that the increase in available plug-in slots that can be achieved with the help of a bridge card is not actually achieved in the related art.

\section{Methodology}

The total Methodology is divided into following steps-

1. Data Collection

2. Processing of Data

3. Experimental work on the collected Data

This is a smart application where the users have to register themselves initially and later, they can login using proper credentials which will help them to access various information regarding their identity under a single platform.

This application contains two modules: User and Admin.

User Module: User Registers/Logins to system to access their personal details and view their information. Users can update their profile. Logout at the end of session.

Admin Module: Logins to system. 
Responsible for maintaining and checking user details, provide access permission to user. Logout at the end of the session.

The Software architecture is shown in Figure

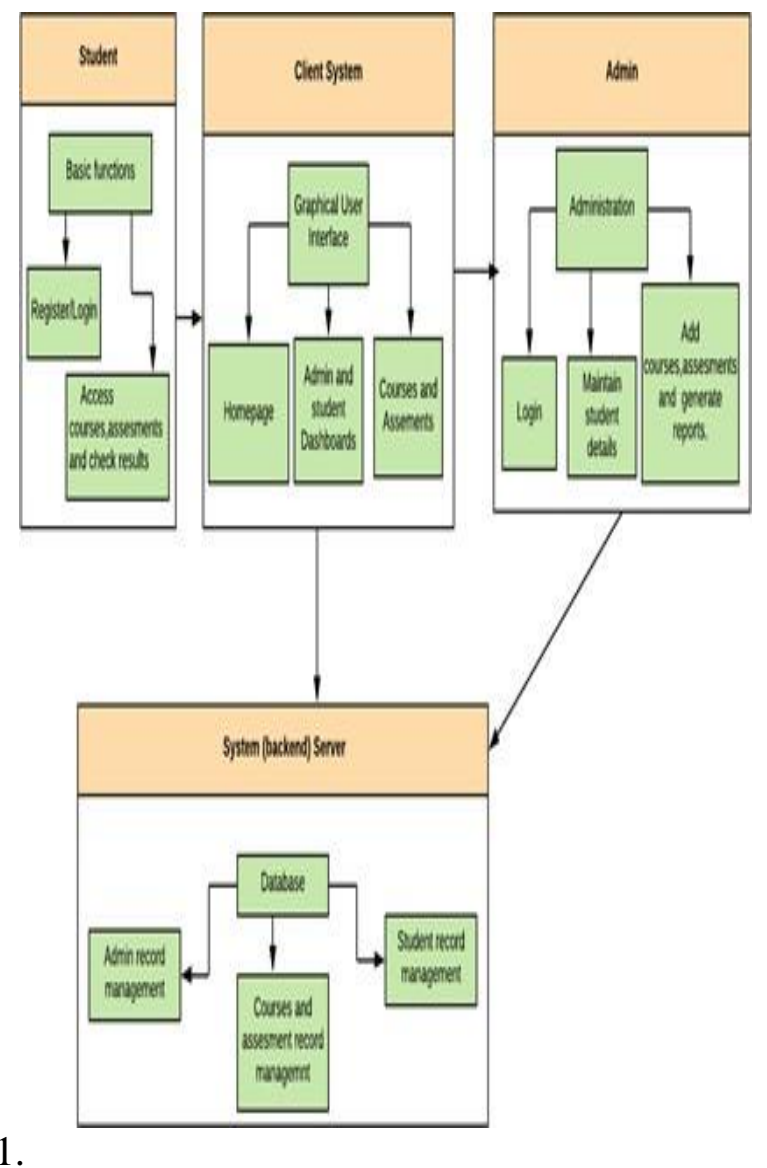

Figure 1: Software Architecture

The various data are collected for the experiments.

A Proof of identity such as passport, Aadhaar, ration card, PAN card or driver's license is mandatory to issue essential items such as electricity, water, mobile phone SIM cards, etc. Those without proof of identity are often unable to obtain such basic items. Aadhaar is expected to be the only identification necessary and sufficient to obtain a wide range of services. While Aadhaar is practically mandatory for the services, its legal status is uncertain as the matter is sub-judged under the Supreme Court of India.
Aadhaar (English: foundation or base) is a unique 12-digit identity number that can be obtained voluntarily by residents or passport holders of India, based on their biometric and demographic data. The data is collected by the Unique Identification Authority of India (UIDAI), a statutory authority established in January 2009 by the Government of India, under the jurisdiction of the Ministry of Electronics and Information Technology, following the provisions of the Aadhaar (Directed Delivery of Financial and Other Subsidies, Benefits, and Services Act), 2016.

The Indian Ministry of Foreign Affairs issues an Indian passport to Indian citizens for international travel. It allows the bearer to travel internationally and serves as proof of Indian citizenship under the Passport Act (1967). The Passport Seva (Passport Service) unit of the Ministry of Foreign Affairs Consular, Passport \& Visa (CPV) Division functions as the central passport organization and is responsible for issuing Indian passports on demand for all eligible Indian citizens. Indian passports are issued at 93 passport offices located. Ration cards are an official document issued by state governments in India to households that are eligible to buy subsidized food grains from the Public Distribution System (under the National Food Safety Act). They also serve as a common form of identification for many Indians. Under the National Food Security Act, all Indian state governments have to identify households that are eligible to purchase subsidized food grains from the Public Distribution System and provide them with ration cards. There are two types of ration cards under NFSA:

A Permanent Account number (PAN) is a ten-character alphanumeric identifier, given as a covered "Container card", by the Indian Income Tax Department, to any "individual" who applies for it or to whom the division designates the number without an application. A PAN is a special identifier gave to all legal substances recognizable under the Indian 
Income Tax Act, 1961. The annual assessment PAN and its connected card are given under Section 139A of the Income Tax Act. It is given by the Indian Income Tax Department under the oversight of the Central Board for Direct Taxes (CBDT) and it additionally fills in as a significant verification of ID. In India, a driving permit is an official report that approves its holder to work different sorts of engine vehicles on roadways and some different streets to which people in general approach. In different Indian states, they are managed by the Regional Transport Authorities/Offices (RTA/RTO). A driving permit is needed in India by any individual driving a vehicle on any parkway or other street characterized in the Motor Vehicles Act, 1988. An advanced photograph of the driving permit can likewise fill huge numbers of the needs of a personality card in non-driving settings (confirmation of character (for example when opening a ledger) or age (for example while applying for a portable association).

\section{A. Processing of Data}

For processing the collected data, we have created different databases for each card where in all the various information of the cards are stored in it.

For this survey we have undergone the following steps and strategy.

Step 1: We have collected the details about the existing cards like Aadhaar Card, Ration Card, Driving License, PAN Card, Voter ID.

Step 2: We collected the existing implementation of Smart card.

Step 3: Collected responses to questionnaire and surveyed results on similar questionnaire.

Step 4: Studied various kinds of smart cards and its applications.

Step 5: Studied the security feature of All-in- one Card.

\section{Software requirements}

Operating System- Windows 7 or Higher Server Side Scripting - PHP

Client side Scripting-JAVA SCRIPT Web

Technology-HTML, CSS

Web Server-APACHE Backend -MYSQL

\section{Security}

A card body which incorporates a micro processor device, a read only memory device and a secure linear feedback shift register, the microprocessor device being interfaced to the read only memory device containing a pre- initialized personality configuration, said pre-initialized personality configuration being comprised of both a unique card identification and a customized secure linear feedback shift register initial configuration a reference linear feedback shift register incorporated in said card body and synchronized to the secure linear feedback shift register. a security code generator incorporated in said card body and producing a security code utilizing said secure linear feedback shift register and said reference linear feedback shift register, said secure linear feedback shift register and said reference linear feedback shift register being driven by a common free running clock oscillator and providing outputs which, when combined with the card identification, produce a security code uniquely based upon said pre-initialized personality configuration, said security code being accessible by the microprocessor and a communication interface incorporated in said card body and connected to said microprocessor device, said communication device providing an input/output message function of the secured information between the microprocessor and an agent outside the secure card body.

The secure card, the security code generator produces a security code to uniquely identify the secure card by providing a synchronization 
key produced by the reference linear feedback shift register, a state of the secure linear feedback shift register, and a card identification at the time of card transaction authentication The Use Case outline is appeared in Figure 2.

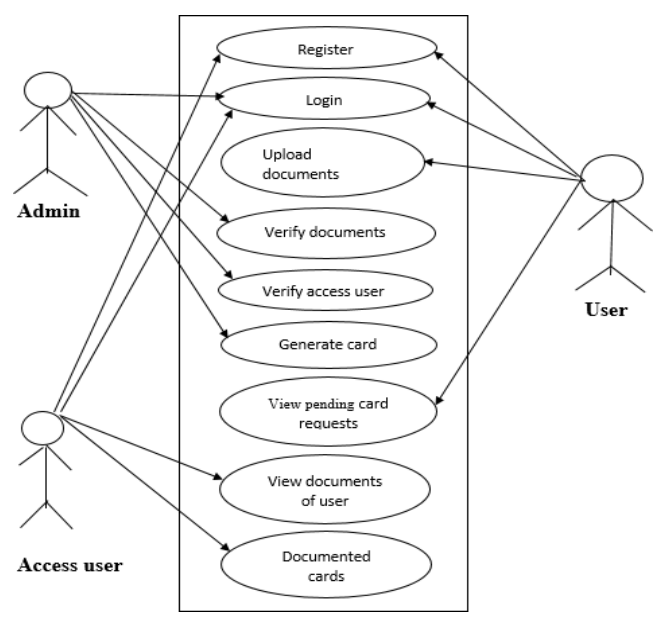

Figure 2: Use Case diagram

The major advantages of this methodology are:

- No need to carry different cards at the same time as all the information will be available in a single card.

- Pin is being provided to user for security, as it may be misused by other person.

- Provides necessary information in single click.

- Easy to maintain.

The System is designed so that it should be accessible $24 \times 7$.

Security - The data should be available to authorized users.

Performance - The system should perform in an efficient way.

Reliability - The system should be reliable and work in consistent manner.

\section{Results}

The data collected is stored in the database, MySQL is used as backend. Server side PHP scripting is used The client side java script is used. Once the application is developed it is hosted on the website. Apache web server is used. The application can be run on windows 7 operating system machine.

Initially the application is hosted and executed. The result of execution is shown in Figure 3.

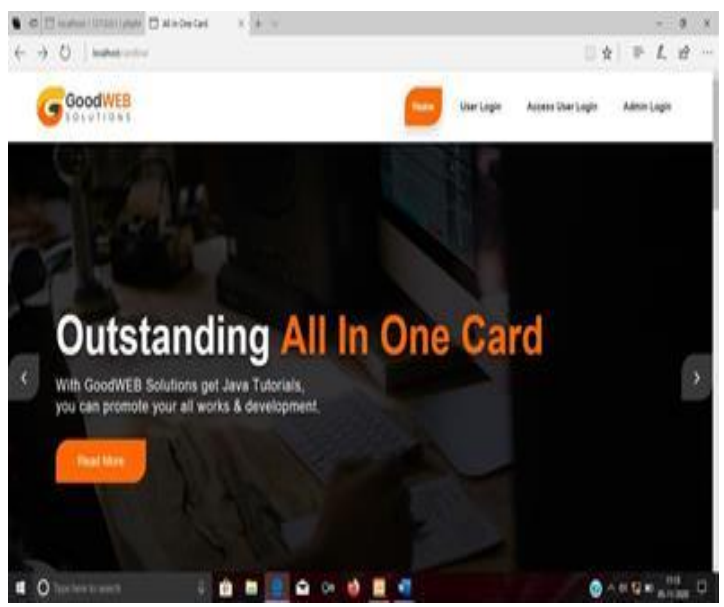

Figure 3: Output of the home page

The user registration can be done by filling all the required details which will be used further. The user registration page is shown in Figure

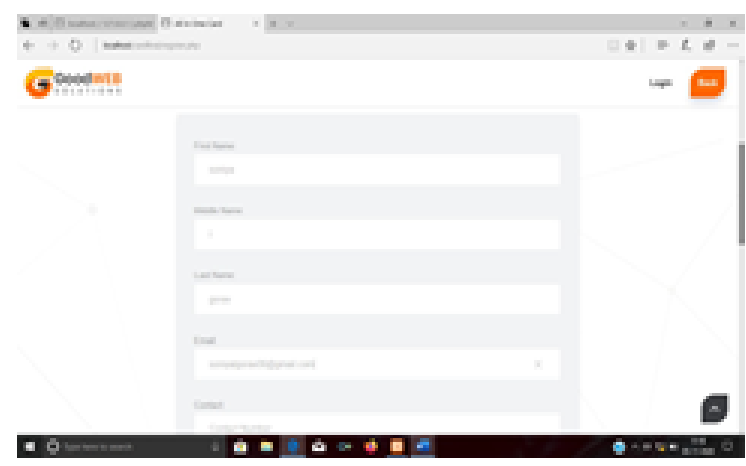

4.

Figure 4: User Registration

Once the details are entered then it is possible to view the user details (Figure 5) which can be down loaded. 

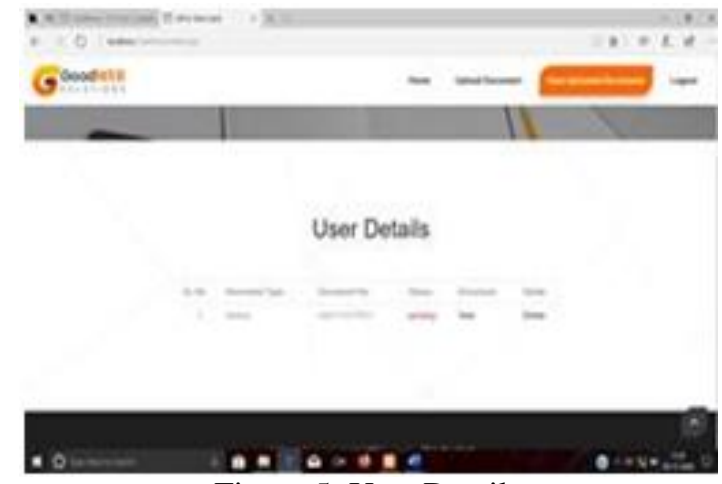

Figure 5: User Details

The downloaded document is shown in Figure 6.

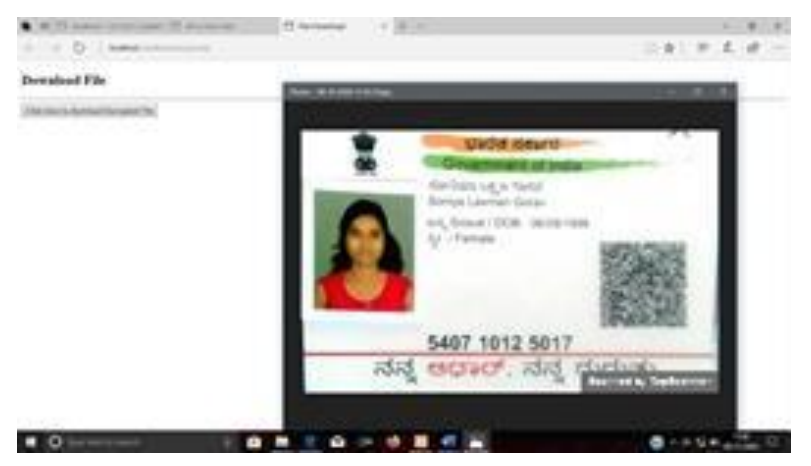

Figure 6: User Details display

The various functions are possible where the details of all the users can be viewed and verified as shown in the Figure 7 and can be downloaded.

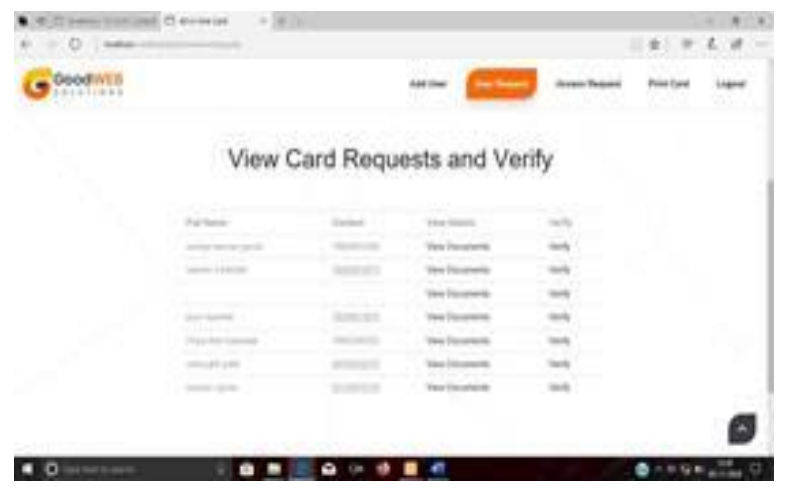

Figure 7: Verification of the card

The final display of the desired user is shown in Figure 8.

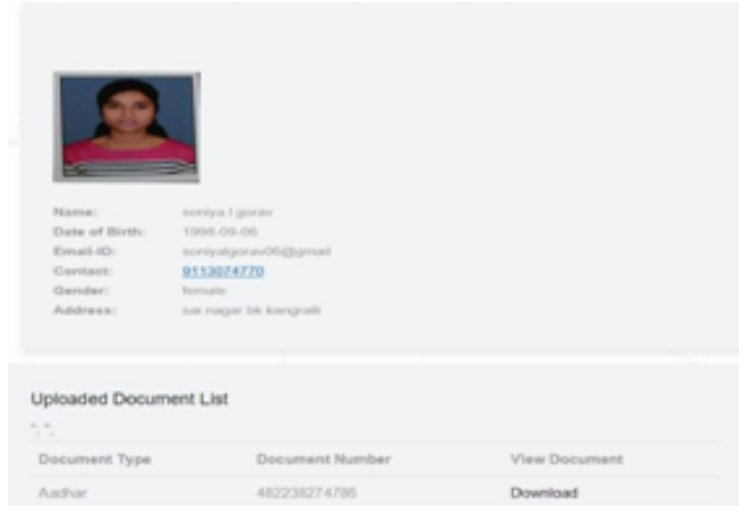

Figure 8: Final display of the desired user

\section{Conclusion}

This application with a card that will contain the general data of the person with several cards such as ration card, voter identification, PAN card, driver's license, etc. has been executed. Here the client will receive a card with a special barcode in that. In the card, the customer must add all the cards in a single card that will be connected through a web application. As long as this is done, you will get a different PIN number to access the application, when you get the PIN no, you will be able to use the single card with all the data from multiple cards at any point you need. At Future we can give updates to customers by SMS once the card is produced and we can even install a central processor on the card to examine the data.

\section{References}

1. Peng Hu. Wei Dai. Enhancing Fault Tolerance based on Hadoop Cluster. International Journal of Database Theory and Application, Vol.7.No.1, January 2014, 37-48. http://dx.doi.org/10.14257/ijdta.2014.7.1.04

2. Florin Dinu, T. S. Eugene $\mathrm{Ng}$, Understanding the Effects and implications of Compute Node Related Failures in Hadoop, HPDC'12, June 18-22, 2012, Delft, The Netherlands,

3. Vishal S. Patil,PravinD.Soni, Hadoop Skeleton \& Fault Tolerance in Hadoop Clusters, International Journal of Application 
or Innovation in Engineering \& Management, Vol.2, Issue 2,February 2013, 247-250.

4. Mohammad Asif Khan, Zulfiqar A. Memon, Sajid Khan, Highly Available Hadoop NameNode Architecture, Proceedings of the International Conference on Advanced Computer Science Applications and Technologies (ACSAT) 26 $6^{\text {th }}-28^{\text {th }}$ November 2012, Kuala Lumpur, Malaysia.

5. Getting started, http://docs.hortonworks.com, Date of publication $28^{\text {th }}$ May 2018.

6. Dhruba Borthakur , [E-book], The Hadoop Distributed File System: Architecture and Design, The Apache Software Foundation, (2007)

7. Jeffrey Dean and Sanjay Ghemawat, Map Reduce: Simplified data processing on large clusters, Proceedings of the Sixth Symposium on Operating System Design and Implementation, December 6 - 8, 2004, San Francisco, CA, United States, 137-149.

8. Jeffrey Dean and Sanjay Ghemawat, Mapreduce: A Flexible Data Processing Toc• Communications of the ACM, Vol. 53 No. January 2010, 72-77

9. Joel Spolsky, Can Your Programmir Language Do Thi: http://www.joelonsoftware.com/items/2006/0 01.html, published on August 1, 2006
10. Tom White, Hadoop: The definitive guide, O'Reilly, Beijing, Cambridge, Third Edition, 2012.

11. Dhruba Borthakur, HDFS Architecture Guide, 2008.

hadoop.apache.org/docs/r1.2.1/hdfs_design.pdf

12. Florin Dinu, T. S. Eugene Ng, Analysis of Hadoop's Performance under Failures, Technical report, August 11, 2011, https://hdl.handle.net/1911/96398

13. Bahman Javadi, Derrick Kondo, Jean-Mare Vincent and David p. Anderson, Discovering Statistical Models of Availability in Large Distributed System: An Empirical Study of SETI@home, IEEE Transactions on Parallel and Distributed Systems, Vol.22, No.11, November 2011. 1896 - 1903.

14. Samir Jafar Axel Krings, and Thierry Gautier," Flexible Rollback Recovery in Dynamic Heterogeneous Grid Computing" IEEE Transactions on Dependable and Secure Computing, Vol 6, Issue 1, January 2009, 3244.

16. Jorge-Arnulfo Quiane-Ruiz, Christoph Pinkel, Jorg Schad, Jens Dottrich, RAFT at Work: Speeding-Up MapReduce Applications under Task and Node Failures, Proceedings of the ACM SIGMOD International Conference on Management of Data, SIGMOD 2011, June 12-16, 2011, Athens, Greece. 